\title{
KEYNOTE ARTICLE
}

\section{Exposure and input in bilingual development*}

SUSANNE E. CARROLL

University of Calgary

(Received: June 15, 2015; final revision received: November 01, 2015; accepted: November 06, 2015; first published online 29 December 2015)

A growing literature on bilingual development explores relationships between language exposure and learning outcomes. Vocabulary size and pace of grammar learning have been claimed to be causally related to amounts or types of exposure to each language. Strong claims are made about the role of exposure on bilingual outcomes. Some researchers posit a unique learning result: a 'weak language'. In a critical review, I voice reasons for scepticism that quantity or quality of exposure alone will explain findings. Central constructs are not well defined; inappropriate research methods have been used; the right kind of data is not discussed. Crucially, authors prevaricate on the notion of language itself, switching between cognitive and environmental perspectives. Both are needed to interpret bilingual behaviours but play different roles in the construction of learner grammars.

\section{Introduction}

\subsection{Themes and goals}

A growing literature on bilingual development explores relationships between language exposure and learning outcomes. Correlations have been found between measures of exposure to a particular language and measures of vocabulary size in each of a bilingual child's languages (Gathercole \& Thomas, 2009; Patterson, 1998; Place \& Hoff, 2011; Scheele, Leseman \& Mayo, 2010). Bilingual children show delays relative to monolinguals on measures of grammatical knowledge, and these too correlate to measures of exposure (Gathercole, 2002a, 2002b, 2002c; Gathercole \& Thomas, 2009; La Morgia, 2011; Paradis, 2010; Paradis \& Navarro, 2003; Thomas \& Gathercole, 2007; Thomas, Williams, Jones, Davies \& Binks, 2013; Unsworth, 2013). Some researchers have linked amounts of exposure to language dominance, that is, to a preference in the child to use one language instead of the other. Language dominance then is linked to a cognitive result: a contrast between a 'strong language' and a 'weak language'. The contrast turns on observable differences in mean length of utterance (MLU) values, particular types of errors in speech production, and preferred directionality of code switches (from the strong language to the weak one) in bilingual spontaneous conversation (Bernardini \& Schlyter, 2004;

* I would like to thank the editors, Harald Clahsen and Jubin Abutalebi, for the opportunity to discuss input and language acquisition. I gratefully acknowledge comments from reviewers which have led to significant improvements to the manuscript. Finally, I want to thank my husband, Jürgen M. Meisel, for many years of enriching discussions about first and second language acquisition.
La Morgia, 2001; Lanza, 1992, 1997; Schlyter, 1993; Yip \& Matthews, 2006). Crucially, the linguistic behaviours in the weak language are attributed to the child's grammar which, in turn, is attributed to the child's experience with the target language. Differences between weak and strong language grammars are attributed to differences in the quantity and quality of exposure.

Overall, two types of conclusions have emerged: a general conclusion and some specific ones rooted in details of individual studies. The general conclusion is: differential patterns of exposure matter to bilingual language acquisition. This conclusion will be briefly discussed in Section 3.1. One specific claim is: the quantity and quality of exposure to a given language matters regardless of the particular linguistic phenomenon under investigation. In other words, researchers generalize from the study of one narrow phenomenon, say vocabulary, to broad conclusions about the nature of bilingual acquisition. In Section 3.2, I will argue that this rhetorical strategy is a bad idea. In the absence of explicit models of learning problems, including some discussion of relevant input, a 'one mechanism fits all learning problems' approach is hardly compelling. Indeed, we will not make progress until researchers start making precise claims about how particular learning problems can be solved.

A second specific claim is: the quantity and quality of input matter regardless of the age of the learner. In Section 3.3, I discuss the hypothesis that bilinguals sort out into distinct populations based on maturational changes in early childhood (Meisel, 2013). This hypothesis has consequences for research methods given that many studies report data from simultaneous bilinguals (2L1) grouped with data from child L2 learners (Cobo-Lewis,

Address for correspondence:

Susanne E. Carroll, Dept. of Linguistics, Languages \& Cultures, University of Calgary, 2500 University Drive N.W., Calgary, AB, T2N 1N4, Canada susanne.carroll@ucalgary.ca 
Pearson, Eilers \& Umbel, 2002a, 2002b; Oller \& Pearson, 2002). If Meisel is correct, this practice will fail to capture important differences between the groups, in particular differences between children who have distinct mother tongues (L1s). ${ }^{1}$ One goal of this paper is to emphasize that mental grammars and lexica belong to individuals, not to groups. Accordingly, it is inappropriate to argue from grouped data to conclusions about the quantity and quality of exposure precisely because the point of such arguments is to attribute a causal role for specific properties of environmentally available language on individual mental grammars. ${ }^{2}$ Meisel's hypothesis also matters for studies of bilinguals focusing on latelearned phenomena (Gathercole, 2002a,b,c; Gathercole, Thomas \& Laporte, 2001; Unsworth, 2013). While the decision to examine learners beyond the age of 3 or 4 is essential to discussions of the ultimate outcomes of bilingual acquisition, we must first ask: Why are some phenomena acquired early and some late? While one can readily find claims that what is acquired early is acquired early precisely because relevant input is frequent while what is acquired late is acquired late because relevant input is infrequent, actual data is hard to come by and convincing demonstrations are even rarer. Explaining even superficially simple learning problems turns out to be hard.

A third specific claim is: It is possible to define a threshold for 'adequate input' such that when the threshold is not met, children will automatically develop a weak language. The Weak Language Hypothesis will be contrasted with processing accounts of the same data in Section 3.3. The main goal of this discussion is to reiterate Grosjean's $(1985,1989)$ assertion that the bilingual is not "two monolinguals in one person". It is unsound to start from a hypothetical, and probably unattainable, notion of a balanced bilingual who is equally proficient in each language and indistinguishable from monolinguals in all communicative contexts and all registers. ${ }^{3}$ Oller (2005) puts the matter so: the bilingual's knowledge of each language, especially knowledge of vocabulary, is 'distributed' across the social and cultural contexts in which each language is typically used. This fact has obvious consequences for the size of the

1 To be fair, some of the data in Oller and Eilers (2002) is presented in such a way that it is possible to discern differences due to some participants being L1 learners of Spanish/L2 learners of English, while others are L1 learners of English/L2 learners of Spanish.

2 Several studies discuss language shift in individuals and language loss in communities. See Eilers, Oller \& Cobo-Lewis (2002), Gathercole (2005), Thomas \& Gathercole (2005). The idea (Pearson, 2007) is that language shift is due to inadequate amounts of input. This perspective is probably naïve (Mougeon and Beniak 1991).

3 A register is a variety of language whose sound, grammatical and meaning choices depend on a number of complex contextual and social factors. See Gregory \& Carroll (1978) for relevant discussion. child's vocabulary in each language, the speed with which words will be activated, the ease with which a speaker discusses certain topics in a given language, and so on.

This discussion will then lead us to a consideration of how the child's developing sociolinguistic identity as a member of a family and as a member of a larger community might play a role in explaining some important observations of De Houwer $(2007,2014)$ related to language choice in the family. Learners' belief systems and identity are not normally part of the analyses of grammarians but they are part of the story of differential outcomes to bilingual learning. This becomes especially obvious when we access carefully designed, large-scale longitudinal studies of older learners, such as that provided by Mougeon and Beniak (1991). Exposure will interact with learner beliefs in complex ways. Only by conducting detailed studies of particular learning problems, with good information on the language use profiles of particular types of learners (bilingual first language learners, early child L2ers, late child L2ers) will we be able to unpack the complexity.

Before I turn to these matters, I will deal with definitions of basic terms and methodological matters in Section 2.

\section{Terminology and conceptual foundations}

\subsection{Exposure versus input}

There is no consensus on the right word to describe the learner's interactions with the environment. Some researchers use the term EXPOSURE; others (Grüter \& Paradis, 2013; Kalishnikova, Mattock \& Monaghan, 2015) use the term EXPERIENCE instead. Some authors switch between the term EXPOSURE and INPUT. Most fail to define any of these terms, using them in a pre-theoretical way. Given the complexity of the issues, terminological precision is needed. I shall use the term EXPOSURE to discuss what is observable and measurable in a particular learning context, for example, what can be found in recordings of child-directed speech (CDS). In my own work in which adults are presented with controlled stimuli drawn from a language they do not know (Carroll, 2012, 2014), we count "exposures" to a given stimulus in order to draw conclusions about what learners have attended to and mentally represented. I am looking at 'first exposure learners' precisely because we can control exactly the learner's contact with the target language. In my work, I often impute particular analyses of the stimuli to our learners, hypothesizing, for example, that segmentation of novel sound forms is facilitated when the sound form is bounded on one side by a pause and on the other side by a recurring word (e.g., ... Conjunction Target Pause) but such claims are part of our inferences and 
argumentation. There are no 'conjunctions' in the stimuli and even 'pauses' are a cognitive construct (Boomer \& Dittmann, 1962; Butcher, 1981; Carpenter \& O’Connell, 1988). I will use the term INPUT for constructs which are relevant to the solution to a particular learning problem, following a long tradition in learnability theory. If a given learning problem requires an abstract construct, e.g., pause, syllable, subject, or verb, then we may claim such constructs as part of the INPUT but we may not thereby claim that the learner has been exposed to them. Of course, we need the physical record, but for most researchers, what is really relevant is the construct INPUT and many simply take it for granted that familiar notions like 'pause' or 'subject' are in the signal. I want to emphasize that there are many layers of learning and processing between the signal and constructs like 'verb' that we must impute to learners, and we have to show that learners are sensitive to them before we can make any claims about what is environmentally available. I return to the relationship between learning and processing below.

This brings me to an important fact about attributing causal properties to input: there is no direct evidence for input in the signal. 'Verbs', 'subjects', 'V2 positions', even 'syllables' are not directly instantiated in the speech signal. Accordingly, everyone must work backwards from demonstrations of what learners have learnt to conclusions about causal factors present in the environment. One can control one's inference process tightly by controlling and describing carefully one's stimuli, counting the number of exposures to it, and limiting the time period between exposure and measurement of learning outcomes, as we and others have done (Cartmill, Armstrong, Gleitman, Goldin-Meadow, Medina \& Trueswell, 2013; Gullberg, Roberts, Dimroth, Veroude \& Indefrey, 2010; Kalishnikova et al., 2015; Medina, Snedeker, Trueswell \& Gleitman, 2011). Through careful controls of stimuli and the learning context, one increases the likelihood of discovering just how learners use environmentally available information. Alternatively, one can speculate. Much of the bilingual exposure literature making claims about quantity or quality of exposure is little more than speculation, built from a 'logic' about amounts of exposure that will not bear close scrutiny.

Recently some researchers on bilingual exposure (e.g., Gathercole et al., 2001) have begun to advert to the insights of the Competition Model (MacWhinney, 1987, 2005) and its discussion of cues, cue reliability, and cue validity. This is all to the good. Still it needs to be emphasized that cues don't come for free, theoreticallyspeaking. Most of the cues adverted to in the literature are abstract (hence not in the signal). Accordingly, cues have to be imputed to mental representations in the learner's mental grammar. Either acquisition mechanisms identify cues guided by a priori biases (some of which will be innate), or else the cues have previously been induced. Either way, there has to be a story which tells us how acquisition mechanisms identify cues as a potential solution to a given learning problem, meaning that we have to embed language acquisition in a theory of speech and language processing. See Carroll (2001) for discussion.

Doing this presents great challenges. Fodor (1998a, 1998 b) pointed out that if a learner has not acquired some distinction, then he has not represented it or not represented it in the right way in his grammar. Since processors, by definition, implement grammars, they cannot analyse any distinction not currently represented in the learner's grammar. The challenge is to explain how relevant novel (= not yet represented) distinctions get into the system. This question is largely unresolved at present but there has been enough work on "bootstrapping" to suggest that a potential solution involves learners using information already encoded in one kind of representation, say, semantic structures, to create distinctions in another, say, morphosyntactic structures (Bonatti, Peña, Nespor \& Mehler, 2005; Morgan, 1986, 1990; Morgan \& Demuth, 1996; Naigles, 1990; Weissenborn \& Höhle, 2001; inter alia). Discussions of 'cue-based' learning often involve precisely this kind of induction and underline the point made above that INPUT is itself a part of some mental representation and not directly in the speech signal.

To sum up this point, Fodor's work tells us that, at the least, we have to make a distinction between types of input. On the one hand, we need to talk about INPUT-TOLANGUAGE-PROCESSORS, e.g., bits of the speech signal that are fed into language processors and which will be analysable if the current state of the grammar permits it. On the other hand, we need a distinct notion of INPUT-TOTHE-LANGUAGE-ACQUISITION-MECHANISMS, which will be whatever it is that those mechanisms need to create a novel representation. For most of the learning problems that we are interested in, the input-to-the-languageacquisition-mechanisms will not be coming directly from the environment.

\subsection{Learning problems}

I have already referred to phenomena to be acquired as 'learning problems' and they will be discussed here in terms of the mental representations we hypothesize learners must compute. Accordingly, learning problems are, by definition, phenomena which must be mentally represented in the grammar in a particular way. Only when the child has the correct mental representations is she said to have 'learnt the phenomenon' or 'solved the learning problem'. In short, I define learning in terms of the contents of learners' mental grammars, not in terms of learner behaviours, maintaining a now 
well-known distinction between competence and performance. For example, a learner will be said to have 'learnt the English past tense' only when he has solved several distinct learning problems that include encoding a general rule or schema that constructs the word by combining a past tense morpheme with a verb stem, e.g., Verb + Past Tense \{lighted, righted, sighted, touted... $\}$. Encoding such a rule presupposes that the learner has already encoded at least a few such forms, presumably alongside bare forms \{light, right, sight...\} and/or present tense forms \{lights, rights, sights... \}. By hypothesis, such representations in memory form the basis for extracting the generalization. In addition, learning the English past tense involves learning phonological rules for verbs where the past tense $-\mathrm{V} d$ is marked only by a consonant, and where the consonant surfaces as [ $\mathrm{t}$ ] when it follows a voiceless final consonant of the Verb: \{baked, talked, worked, zipped... $\}.{ }^{4}$ Additional assumptions must be made for partially regular past tense forms where the Verb stem also undergoes sound changes: $\{$ deal/dealt, feel/felt, kneel/knelt, sleep/slept ... \} and for other even less regular cases. ${ }^{5}$ Clearly, exposure to English is required to learn all of these verbs; speakers of Chinese do not know them. Less trivial is the claim that exposure to each past tense form is not required for a learner to be able to produce it. That claim is testable and a great deal of evidence suggests that it is correct (see Marcus, Pinker, Hollander, Rosen \& Xu, 1992; Pinker, 1999). Also interesting is the question as to which forms are acquired first and how the underlying form of the morpheme $-\mathrm{V} d$ is ultimately discovered. Frequency of tokens in CDS may be important, but frequency of verb types turns out to be equally important (Bybee, 1995, 2007), raising obvious questions as to how children discover that the various tokens they hear in the signal are all instances of the 'same word'.

\subsection{Methodological matters}

\subsubsection{The problem with group data}

Given the discussion so far, it will not be surprising that I take a dim view of drawing conclusions about exposure and input from group results, a practice which is typical of the large-scale studies cited above. Groups of children do not have mental grammars, only individuals do. At the same time, studies of large samples are greatly needed. We cannot rely on case studies of single children or small-

4 In the rule provided "V" is an underspecified vowel that will be pronounced as an unstressed, centralized vowel sound, typically [i] or [ə].

5 While there is consensus that irregular past tense forms are somehow coded "in the lexicon", there is no consensus on how this coding takes place. See Marcus, Pinker, Ullman, Hollander, Rosen \& Xu (1992) arguing for "rules" and associative learning versus Yang (2002), arguing for rules alone. sample case studies whose participants constitute samples of convenience, for the obvious reason that we cannot know how typical the children in the single case studies are. If reporting individual results can be done in large(r) sample studies, it would be a good thing.

\subsubsection{The problem with parental language use questionnaires}

Paradis and Genesee (1996), who are much cited in the exposure literature, have taken it as a matter of logic that children who are exposed to two languages from birth must be getting less exposure to each language than monolingual children. The logic goes this way: there are a finite number of hours in the day (24); children are awake and potentially attentive to language during some subset of those hours (say, 8); the time available to learn is split between two languages; ergo, bilingual children must be getting less exposure, e.g., fewer than 8 hours. From this perspective it may seem like a perfectly reasonable methodological decision to rely on questionnaires in which parents are asked to estimate how much time they spend with their children and what languages they are using when they do so. However, temporal units are crude measures of exposure and they tell us nothing about input.

The logic of Paradis \& Genesee's claim also presupposes that language use can be neatly divided into the use of one language or of the other. However, bilinguals code-switch on a regular basis and can do so, controlling their speech choices phonetically, lexically or syntactically (Grosjean, 1982; Auer, 1998). In some communities, the most frequent code-switches involve single words (Poplack, Wheeler \& Westwood, 1989). Such code-switches are different in nature from loanwords (Budzhak-Jones \& Poplack, 1997; Poplack \& Sankoff, 1984). Is there any reason to think that that naïve speakers can accurately distinguish and label such cases? It certainly is doubtful that questionnaires that force a choice between one language or the other will provide us with an accurate picture of amounts of use of each language. While one can develop questionnaires to estimate the amount of mixed language parents are using (Byers-Heinlein, 2013), even they will not deal with the essential problem which is the problem of defining language itself. Questionnaires that ask parents about their language use all draw on what Chomsky (1986) has called E(XTERNAL)-LANGUAGE notions of language. They assume that labels like 'Spanish' or 'Welsh' are objectively definable entities which speakers can make sense of and accurately apply. However, this is doubtful. Is a phonetically and grammatically unadapted English word in an otherwise Spanish utterance 'Spanish' or 'English' or something that is neither? Is an English word that is phonetically and grammatically adapted to Spanish 
'Spanish' or 'English' or something that is neither? ${ }^{6}$ Why would we assume that parents can make clear decisions in such cases and why would we assume that two different parents are making the same decision? Finally, parental responses will not tell the researcher how the child is dealing with the classificatory problems that mixed language present. Does the child treat them as 'noise', that is, as exposures that are irrelevant to a particular learning problem in a given language? Given plenty of evidence that learners are selective in analysing the speech they are exposed to, the idea that all aspects of the signal matter all the time seems implausible.

A separate problem is that parents are not able to reliably estimate how much speech they actually use with their children (Grüter, Hurtado, Marchman \& Fernald, 2014). Crucially, studies that actually measure childdirected speech (CDS) in homes where two languages are regularly used report considerable variation in the absolute amount of talk produced in each language by parents. De Houwer (2014) examined conversations in Dutch involving a sample of 16 Dutch-French bilingual families and a comparison group of 30 Dutch-speaking families. Mothers were recorded interacting with their child during play sessions and meal times at two points in developmental time (when the children were 13- and 20-months-old). Transcripts from 184 recordings were analysed for 6 different kinds of linguistic units (turns, utterances, word types, word tokens, morphemes, and syllables). No differences were observed between Dutchspeaking mothers of monolingual and bilingual children but there were great differences among individuals in each group. Some mothers were really chatty and some were not. ${ }^{7}$ Weisleder and Fernald (2013) reported similar findings based on recordings over a 10-hour period of all the speech spoken in the vicinity of 29 children from Spanish-speaking families from Miami. One toddler was exposed to more than 12,000 words over the ten hours, while a second child was exposed to only 670 words. This works out to 1500 words per hour for one child but only 600 words per hour for the other. In short, there are no reasons to assume that one can readily convert the number of hours that parents spend with children into a reliable

6 A grammatically adapted noun would be marked for gender; a grammatically adapted verb would be marked for verb class and tense, and so on.

7 For example, in the transcripts arising when the child was 13 months, the measures included the range in number utterances per turn (monolinguals: 13-103; bilinguals: 24-97), the range in the highest number of morphemes per utterance (monolinguals: 7-27; bilinguals: 7-18), the range in the mean number of words per utterance (monolinguals: 2.23-3.91; bilinguals: 0-4.33), the range in the number of word tokens (monolinguals: 3-306; bilinguals: 0-481), the range in the number of word types (monolinguals: 58-263; bilinguals: 55$269)$, the range in the highest number of syllables per utterance (monolinguals: 8-28; bilinguals: 7-20), and the range in the number of morphemes (monolinguals: 110-782; bilinguals: 142-997). measure of quantity of CDS. Time is not a good measure of exposure.

\subsubsection{The problem with standardized measures of vocabulary knowledge}

The vocabulary studies cited above have made use of measures of vocabulary that invariably turn out to be measures of nouns that can readily be associated with referents represented in pictures. These nouns are presented outside of any linguistic or social context. Some researchers (Pearson, Fernández, Lewedeg \& Oller, 1997) make clear that they think of words as Saussurean associations of sound forms and images. Certainly, this view of words is embodied in the Peabody Picture Vocabulary Test (PPVT), the Picture Vocabulary test, the vocabulary test used by Gathercole and Thomas (2009) and the version of the Diagnostic Test of Bilingualism used by Scheele et al. (2010). Unfortunately, this conceptualization of words just won't do. What matters for language learning are not lists of sound forms devoid of any context but rather the properties that make them combinable with other words and permit us to talk about all the things we want to talk about, including abstract concepts. The word boy differs from the expression byebye precisely in that boy combines with other linguistic units and bye-bye does not. When a child says All gone, looking at an empty bowl that previously contained ice cream, he is commenting precisely on the absence of the ice cream. The complaint here is not that psychologists devote too much time to studying words that are concrete nouns that denote individuals and objects, even less that they make use of standardized vocabulary tests (which, of course, are an important tool), but rather that they extrapolate from what they discover to 'language learning' in general. The extrapolation is questionable; it isn't serviceable even for word learning.

Words are complex units of language consisting of potentially three autonomous representations: prosodic, morpho-syntactic, and conceptual (Jackendoff, 2002). Conceptual representations permit referential speech acts in appropriate contexts but more importantly, they encode predicate-argument structures, ontological categories, semantic roles and many other constructs that vocabulary tests never test. Research shows that these aspects of word meaning emerge slowly and incrementally. Unquestionably, the process is exposure-dependent (see Bloom, 2001, for discussion).

In contrast, segmentation and the mapping of sound forms to referents are rapid and can occur on the basis of as little as two exposures to a word in a context which makes the referent salient. This phenomenon has been called FAST MAPPING and it has been studied in monolinguals, child L2ers and adult L2ers (Carey \& Bartlett, 1978; Carroll, 2012, 2014; Casenhiser \& Goldberg, 2005; Elley, 1989; Gullberg et al., 2010; Heibeck \& Markman, 1987; 
Markson \& Bloom, 1997; Rohde \& Tiefenthal, 2000; Woodward, Markman \& Fitzsimmons, 1994, among many others). In this case, input is necessary, but not much exposure!

In short, measures of vocabulary typically used in the bilingual exposure literature tell us nothing about the kind of exposure a learner needs to form the different kinds of representations that actually constitute 'knowledge of words'. The kinds of exposures needed vary according to the learning problem. Segmentation is virtually instantaneous; sound form-referent associations are equally rapid. However, learning concepts is slow and incremental.

\subsubsection{Chattiness does not equate to quality of input}

Cartmill et al. (2013) have reported on the basis of videorecordings of interactions of parents with their 14-to-18month-old children that English-speaking parents vary considerably not only in the quantity of talk they produce but also in the quality. The focus of the research is on how well parental referential intention is inferable from the context on the basis of gestures like pointing to an object, handling it, gazing at it, and so on. These behaviours are known to be part of conversational interactions and are assumed to help children establish form-referent mappings. Cartmill et al. created short vignettes from the videos they recorded by replacing target words with a beep in the audio portions. 218 adult participants were asked to guess 50 parents' words from the altered videos. Systematic differences were found in how easily individual parents' words could be identified purely from the socio-visual context. These differences were found to correlate with the size of the child's vocabulary three years later. The authors conclude that caretakers whose behaviours facilitate the induction of referents are aiding their child's overall vocabulary acquisition.

Cartmill et al. mention the literature reporting correlations between vocabulary size and quantity of input. They make the point that it is not implausible to think that the chattier a parent is the greater the probability that they will eventually produce speech which is useful to the child. When parents are using THE SAME FORMS THEY HAVE USED BEFORE, chattiness might be an advantage. In this case, the learning problem involves mapping variable sound forms for a word to a referent which can have different visual properties in different contexts. Notice, however, that for other learning problems, say learning an inflectional paradigm (when to use nominative versus accusative case on a noun, for example), saying 'the same thing' will not be helpful. What the child needs to do is to establish contrasts, meaning a correlation between the presence of a given form (the nominative) in a given syntactic context coupled with specific meanings (say, AGENT) and the absence of the same form in a different syntactic context coupled with specific meanings (say,
PATIENT) and a second correlation between the presence of accusative case in that second syntactic context when coupled with the PATIENT meaning. In this case we have to suppose that a chattier parent also produces more variable language to be a helpful parent, but we cannot simply suppose that this is true. We need good data on conversational practice among parents, examined with this specific learning problem in mind.

I would also like to add that the common practice of selecting samples of convenience among graduate students and self-selecting participants (parents who turn out to be white, middle-class, and highly educated) is most unfortunate. We should be concerned about the use of value-laden terms like 'quality' of the input and the implicit claim (a constant theme that runs throughout this literature) that the specific cultural practices of white, middle-class families are inherently 'superior' because they lead to child vocabularies that are temporarily larger. From the perspective of other cultures that value silence and accord it an equally important place in human interactions, those chatty parents must seem like noisy magpies.

\section{Exposure matters to language acquisition, so what?}

\subsection{The general claim}

The general claim from the studies cited is that exposure matters to bilingual language acquisition, especially exposure to the minority language. This claim is trivial and is, moreover, readily conceded by everyone, including those promoting a universal set of constraints on language acquisition (Chomsky, 1986; Yang, 2002). As Berwick, Pietroski, Yankama and Chomsky (2011: 1209) put it: "At a suitable level of detail, everyone can ...

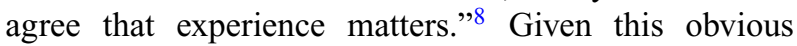
consensus, I plead for a moratorium on studies whose sole theoretical claim is just that exposure to a given language matters. To move us forward, we require detail about how exposure guides specific learning mechanisms (analogy, associative learning, instance-based learning, rule-learning, statistical learning) towards the solution to a well-defined learning problem. Or, conversely, we need detail about how the absence of specific kinds of cues in CDS leads to a clear failure to solve that problem.

\footnotetext{
8 Claims by generativists have been misrepresented. Hoff (2014: 106) writes: "Proponents of the nativist view have long argued that because children all over the world acquire language despite widely differing circumstances, language acquisition could not depend on experience." She fails to cite any sources. Poverty of the Stimulus arguments (Berwick et al., 2011; Piattelli-Palmarini \& Berwick, 2012) are not equivalent to saying that the acquisition of particular languages does not depend on exposure to language.
} 


\subsection{Input depends on the form of the learning problem and so does exposure}

To reiterate, talking vaguely about 'language learning' is uninformative. We need to understand the logical properties of individual learning problems. As we saw above, word learning involves several distinct learning problems, some of which require few exposures and others require repeated exposures to the same forms in the same meaning contexts. Similarly, we saw with respect to the rule of regular past tense formation in English that once learners have extracted a general rule, they do not require exposure to specific instances of the rule. It is enough to hear, e.g., snarf to be able to form snarfed. In other cases, such as learning an inflectional paradigm, learners require exposure to all of the exponents of the paradigm in order to learn the full set of contrasts, including the information that one might use a given form in a given context but should not (because an alternative is preferable). As such examples make clear, it makes no sense to investigate some narrow phenomenon in bilingual acquisition and then make sweeping claims about 'language acquisition' in general. We should expect different exposure profiles depending on the nature of the learning problem.

\section{3 'Bilinguals' are not a single population of learners}

One of the first studies to examine the question of exposure and bilingual acquisition made the claim that children who have a 'weaker language' are actually behaving like second language (L2) learners. Thus, Schlyter (1993) claimed that bilingual Swedish-French children living in Sweden, whose French was weaker than their Swedish, made errors similar to those produced by adult L2 learners of French, e.g., placing weak or clitic personal pronouns (which can only occur in a pre-verbal position) in a post-verbal position ( $*$ Je donne le versus Je le donne 'I give it'). Schlyter used such evidence to argue that these bilinguals had grammars that are substantially different in kind from those of monolingual learners of French and simultaneous bilinguals (2L1) whose French was 'strong' or 'balanced'. For Schlyter and others engaged in the 'weak language/strong language' discussion (La Morgia, 2011; Yip \& Matthews, 2006), the argument is that differences in the quality and quantity of exposure are the causal factors.

Meisel, whose investigations of 2L1 acquisition (Meisel, 1985, 1986, 1989, 1994) inspired Schlyter, has argued that there are principled differences between $2 \mathrm{~L} 1$ and L2 acquisition based on the developmental paths learners follow and the kinds of systematic errors they make when they speak (Meisel, 1991, 1997, 2011). However, in contrast to Schlyter, he attributes the differences in learner grammars to differences in the ways that the brain processes languages. In particular, he argues for maturational changes that begin at around age 3 to $3 ; 6$ that subsequently alter the way children process language. Prior to this, all bilingual children should process the language they hear in the same way as monolinguals. After this age, children may process the language they hear using the mechanisms that late L2 learners use. The crucial factor is not the quantity or quality of the input but rather maturation. Accordingly, Meisel (2007a, 2007b) reviewed the arguments for a 'weak language' and emphasized that there are demonstrable rate of acquisition differences in weaker-language bilinguals but no significant competence differences. Similarly, Bonnesen (2009) carried out a case study of FrenchGerman bilinguals with French as a weaker language. He showed that their grammatical development was slower than that of monolinguals but otherwise comparable.

2L1 children are often not 'balanced bilinguals', in general, or at particular moments in developmental time. For what issues does this matter? Many have claimed that this matters for vocabulary size, but Meisel (2007a, $2007 b)$ asserts that it does not matter for grammar. It should also be mentioned that Schylter (1993) and La Morgia (2011) prevaricate in their terminology, shifting from claims about a 'weaker language' to claims about a 'weak language' but the evidence for the latter is itself not strong. The validity of the claim turns on demonstrating that the mental grammars of bilinguals with a weak language are qualitatively different from the grammars of bilinguals for whom it is a strong language. La Morgia presents 10 different criteria for differentiating weak and strong languages and nine of them relate to performance. ${ }^{9}$

The conclusion that $2 \mathrm{~L} 1$ children can develop a 'weak language' has therefore been contested. The knowledge systems of bilinguals compete during speech and language processing and so the kinds of errors Schlyter and La Morgia describe tell us something about the child's grammars (and ultimately about the operation of learning mechanisms) only to the extent that they cannot be attributed to performance factors like attention and automaticity of control of processing procedures (Bialystok, 1994; Döpke, 2000; Segalowitz, 2003). At the very least, we should demand appropriate statistical analyses of types of errors made by children before concluding that errors can only be explained in terms of the contents of the child's grammar and not in terms of competition between different performance procedures specific to each language. Such quantitative differences certainly do not license the claim that crucial differences in exposure are the causal factor.

\footnotetext{
9 They are: slow rate of acquisition, production of target-deviant forms, limited vocabulary, limited or no code-switching into the weak language, frequent switching from the weak into the strong language, MLU shorter than monolingual child values, MMU shorter than monolingual child values, infrequent initiation of a theme in a conversation in the weak language, avoidance of complex structures, refusal to speak the weak language (La Morgia 2011: 15-16).
} 
Implicit in the rebuttals, however, is an 'everything else remaining the same' argument. In other words, we are to assume that children with a weaker language will develop the same grammars as those with that language as a strong language if they continue to get the same kinds of relevant exposure that they have had up to that point in time. The reality is that amounts of exposure to a given language can change dramatically in a bilingual child's life when parents divorce, when a nanny or babysitter who speaks the minority language leaves the family circle, when the child enters day care or the regular school system, and so on (Silva-Corvalán, 2014). In addition, as Bonnesen's (2009) study reveals, when bilingual children choose to switch into the stronger language or refuse outright to speak the weaker language, parents may use this change in the child's behaviour as a pretext to stop speaking the minority language with their child altogether. In those cases, we can predict that the child will cease to learn phenomena not yet acquired in the absence of relevant input, and may even attrite. In short, the realities of bilingual family life are complex and patterns of language use in the home, including patterns of parental language use (studied via recordings), merit detailed examination. For this reason, well-designed studies of older learners are an essential complement to the studies of young children.

Many of the publications arguing for exposure effects in bilingual development fail to differentiate between simultaneous and sequential learners treating them all as 'bilinguals' (Cobo-Lewis et al., 2002a, 2002b; Oller \& Eilers, 2002; Oller \& Pearson, 2002; Pearson, 2007; Pearson \& Amaral, 2014; Pearson et al., 1997). According to Meisel, we can expect individuals in each of these three groups to have distinct grammars at particular points in development, make unique types of errors, follow different developmental pathways, and end up with different final-state grammars. A processing account of 2L1ers with a weak language asserts that they may have the same competence as $2 \mathrm{~L} 1 \mathrm{ers}$ with that language as a strong language, but implementing that competence in production might be differentially influenced by attention, fatigue, etc. Certainly, a processing account of weaker language behaviours fits well with the idea that different representations compete as the child plans an utterance (MacWhinney, 1987; Costa, Miozza \& Caramazza, 1999; Costa, Colomé, Gómez \& Sebastián-Gallés, 2013; Döpke, 2000; inter alia).

\subsection{Notions of language}

One of the deep problems in making sense of the various claims in this literature is that researchers make use of quite different notions of language. I have already raised the issue of assuming that there is a single, coherent thing called 'Spanish' or 'Welsh' which is what children are learning. We cannot, however, reject e-language notions and claim that we are only concerned with the child's mental grammar (his i-language or internal-language, see Chomsky, 1986). We have to consider the child's emerging beliefs about what language to speak when, to whom, and why (Fishman, 1965). We know very little about the bilingual child's developing sociolinguistic identity at a young age. We also know little about how it changes as the child acquires a social network broader than the nuclear family. Nor do we understand how labels for languages ('English', 'Spanish') are tied up with identity. Given our relative state of ignorance, I see no reason not to assume that a bilingual child may prefer to use one of her languages based on beliefs about the relative importance of that language in the family. Bilingual children develop beliefs about labels like 'English' and 'Spanish' very early on and their beliefs as to what counts as an instance of 'English' versus an instance of 'Spanish' are crucial to understanding their speech behaviours. Their beliefs are probably also relevant to whether they choose to use a particular language at all.

Pearson (2007: 400) invokes a cycle of language use in which children require sufficient exposure to become comfortable using the language, using the language then leads to more input. More input leads to more practice, and more practice leads to more comfort in the language. Mougeon and Beniak (1991) show that this argument is not tenable as stated. They carried out a large-scale carefully designed study of the effects of patterns of language use (based on questionnaire data and interviews) and effects of French-language schooling on language development and language maintenance among FrancoOntarian adolescents. On the basis of recorded hourlong interviews with their participants, they carried out detailed structural and sociolinguistic analyses of the French spoken by the children, comparing their speech to properties typical of French-Canadian varieties, as well as those typical of the normative French the schools attempt to inculcate.

The adolescents came from four communities in Ontario that differed considerably in terms of the proportions of Francophones to non-French-speaking individuals: Hawksbury (a Francophone community), Cornwall, North Bay, and Pembroke (all communities where Francophones are a minority; see Table 1). FrancoOntarians are well integrated into their communities and show high levels of linguistic exogamy. Mougeon and Beniak were especially interested in how linguistic exogamy affects French-language use in the home. Like De Houwer, they were also interested in how parental choices in language use would influence the language use of their children and effects of language use on Frenchlanguage proficiency.

Their study provides clear evidence that, even by grade 12 , participants from minority communities were not target-like (relative to norms defined by the children 
Table 1. Accuracy (\%) of Franco-Ontarian school children on use of reflexive pronouns in obligatory contexts based on community and use of French (adapted from Mougeon \& Beniak, 1991: 57)

\begin{tabular}{|c|c|c|c|c|c|c|c|}
\hline \multirow[b]{3}{*}{ Grade } & \multicolumn{7}{|c|}{ Communities* } \\
\hline & \multirow[b]{2}{*}{ Hawksbury } & \multicolumn{2}{|c|}{ Cornwall } & \multicolumn{2}{|c|}{ North Bay } & \multicolumn{2}{|c|}{ Pembroke } \\
\hline & & High-users & Low-users & High-users & Low-users & High-users & Low-users \\
\hline 2 & 96 & 90 & 78 & 63 & 36 & 64 & 35 \\
\hline 5 & 96 & 99 & 80 & 96 & 72 & 86 & 33 \\
\hline 9 & 100 & 97 & 88 & 95 & 83 & 74 & 70 \\
\hline 12 & 100 & 100 & 94 & 100 & 89 & 89 & 75 \\
\hline
\end{tabular}

${ }^{*}$ At the time of the study, Hawksbury was $85 \%$ Francophone, Cornwall $35 \%$, North Bay $17 \%$ and Pembroke $8 \%$

from Hawksbury). This was especially true of those from homes where family members used mostly English with one another. One phenomenon they reported on in detail was the use of reflexive pronouns in obligatory contexts. While all children improved over time, Mougeon and Beniak (1991: 57) showed that accuracy scores on the use of the reflexive pronouns in obligatory contexts varied depending on which community the children were from. See Table 1 (adapted from their Table 3.1, p. 57).

The Francophones from Hawkesbury were at ceiling; participants from Cornwall, North Bay and Pembroke had decreasing accuracy scores, of $92 \%, 80 \%$ and $64 \%$ respectively, in line with the decreasing size of the Francophones in the population. However, these figures hide important differences between grade levels and patterns of language use. The children from Hawkesbury were at ceiling at Grade 2, meaning that they had acquired obligatory use of the reflexive pronoun sometime prior. All other children had lower scores at Grade 2. The children from Cornwall with high French-use indices scored only slightly lower at Grade $2(90 \%)$ but were at ceiling by Grade 5 . The children from North Bay who had high French-use scores took longer to attain $100 \%$ scores (only by Grade 12) but had high accuracy scores by Grade 5. The children from Pembroke, the community where Francophones were only $8 \%$ of the population, never got close to ceiling. In all the communities where Francophones are a minority, children with low French-use indices scored substantially lower, with scores increasing as the proportion of Francophones in the community increased. It is important to grasp that ALL of these children had been educated entirely in French in French-language schools (from approximately 5 years of age). They were all bilingual, and had clearly been exposed to the verbs they were using erroneously. It is implausible, therefore, to attribute the differences in accuracy scores to differences in exposure. It is also not a question as to whether the children 'knew' the verbs. Rather, it appears that the issue is use of French outside of the classroom for the purposes of oral communication.
The bilinguals who come from homes where English is the normal language of communication and who use English to communicate with peers are simply less practiced at speaking French. Under such circumstances, we should anticipate competition from English processing procedures, lexical knowledge and syntactic constructions and we may predict that the English processing procedures will win the competition some of the time.

Mougeon and Beniak also have something to say about linguistic exogamy and parental language choices. They reported that in linguistically mixed marriages the Frenchlanguage parent typically chose to use English with his or her partner, and may also have used English with his or her children. Even these parents, however, often make the decision that their children should be educated in Frenchlanguage schools. Such choices suggest ambivalence in the parents' attitudes towards their ethnic language. They want to preserve it but the children have to do all the heavy lifting. When there is little support for French-language use among peers and in the broader community, it looks as if the children are not up to the task (see Eilers et al., 2002 for discussion in the Spanish-English context of Miami Florida).

Language use in bilinguals is a matter of choice and reflects a speaker's values and belief systems. Contradictory attitudes among minority language speakers are well documented by socio-linguists and sociologists of language (ORiagáin, 2008; O’Rourke, 2005). ${ }^{10}$ It would be surprising if young children were not able to detect ambivalence in their parents and choose to test parental resolve. In a case study of two GermanFrench bilingual children (François and Christophe) who were dominant in German, Bonnesen (2009: 180) reports that both children refused to speak French for several months (François between 2;09 and 4;03; Christophe

\footnotetext{
${ }^{10}$ Mougeon and Beniak (1991), for example, observe that in one community francophone parents lobbied (and eventually convinced) their French-language school to teach mathematics and the natural sciences in English!
} 
between $3 ; 0$ and $3 ; 3)$. He notes that bilingual children often go through periods when they favour one language over the other in their production. However, in these two cases both mothers responded to the situation by simply not speaking French to their children. It is impossible to state in this case what is cause and what is effect but the parental choice is surely saying something about the mothers' commitment to their children's bilingualism.

In short, the family is the locus of language acquisition AND language socialization. The dynamics of the relationship between the two is not yet understood. De Houwer $(2007,2014)$ examined the relationship between parental language use and whether the bilingual child actually chose to use each of his languages. In families where both parents used the minority language, $97 \%$ of her sample of children spoke both languages. If one parent spoke both languages and the other used the minority language, the choice by the child to use both languages was only slightly lower (93\%). When one parent used only the majority language and the one used the minority language, children chose to speak both languages $73 \%$. When one parent used only the majority language and the other used it and the minority language, only $34 \%$ of children choose to use both languages.

We could, of course, attribute these differences to language exposure, claiming that a child with two minority-language parents will undoubtedly have greater exposure to the minority language than a child whose parent is switching between the minority and the majority language. However, one could also view these numbers as a reflection of the child's observations about what matters to her parents and her emerging beliefs and attitudes about the importance of using the minority language. As De Houwer (2014) emphasizes, bilingualism can be experienced harmoniously or as conflictual. How a child experiences each of these kinds of bilingualism merits further investigation in connection to the consequences they have for the child's grammar.

\section{Conclusions}

From where I sit, it looks as if the bilingual exposure research has been operating largely in a theoretical vacuum. This is a shame. The literatures on both exposure and input in monolingual first language acquisition are very rich and researchers on bilingualism would profit from the insights that have emerged over the last 40 years. It seems to me that moving forward on these complex issues will require defining learning problems in terms of potential solutions, examining directly the speech that learners learn from in interaction with caregivers and siblings, and framing input questions in ways that make sense of both the findings of language processing research and language learning studies. We should keep in mind that input to speech and language processors is not equivalent to the input needed by acquisition mechanisms to encode novel representations. Much unnecessary confusion has arisen from the assumption that input to learning must be found in the environment. Studying the logic of specific learning problems ought to convince us that solutions to many language learning problems will be found in extant mental representations, say, when a learner identifies the subject of a sentence as the NP expressing an AGENT. Looking 'inwards' for the input to learning problems creates obvious methodological challenges. The most productive way to investigate what matters to learning has been to actually describe what learners have learned at some point and then work backwards, making use of rich descriptions of the learning environment in terms of the stimuli used in a learning experiment or descriptions of child-directed speech made from recordings or other forms of direct observation of interactions between caregivers and children. The work of De Houwer and also Mougeon and Beniak demands, however, that we broaden our horizons to consider the consequences of language use on language acquisition. Language use, even in young children, may well depend on the attitudes towards the users of language and the values that we associate with the labels we name it with. This is where the contents of beliefs, attitudes and values, mental constructs all, rub up against the contents of mental grammars and lexica.

We do not normally have proper names for our idiolects but many of us find ways to name the varieties used in our communities. It is just another way to differentiate ourselves from our neighbours. Names like 'Cuban Spanish', 'Scouse' or 'Kölsch', like all words, are meaningful for the people who use them and the meanings result from experience. Children learn in their families to add content to such words and to invest them with emotional value. For example, they can motivate the decision of a Torontonian of Italian heritage to study at school something called 'Italian' and can also explain that person's disappointment and frustration when the content of the language lessons bear little resemblance to the language used by nonna and nonno. They explain why speakers of 'Cantonese' in Vancouver send their children to immersion schools where 'Mandarin' is the medium of instruction.

What learners understand by the labels we use to talk about language may also play a role in explaining language use choices. Accordingly, we should familiarize ourselves with independent traditions on identity and attitudes (Altman, Burstein-Feldman, Yitzhaki, ArmonLotem \& Walters, 2014; Armon-Lotem, Joffe, AbutbulOz, Altman \& Walters, 2014). We should also pay attention to how parents in bilingual families talk about their languages and about linguistic behaviours in the course of socializing their children into their families and linguistic communities. 
The fact that children in bilingual families often refuse to use a minority language - more clearly stated, the language of one or both of their parents - is unfortunate. As De Houwer (2015) emphasizes, it can lead to conflict in a family, to resentments and to an increasing sense of alienation from one's heritage. When the problems affect entire peoples, the consequences become tragic, as the Report of the Truth and Reconciliation Commission of Canada (2012) has made clear. ${ }^{11}$ The literature on lesserspoken languages is full of gloom and doom. Indeed, the situation of many indigenous languages is often described in catastrophic terms. From an e-language perspective, this response makes sense. However, it is important to understand that in engaging in this kind of talk, people are behaving as if language were some objective and clearly defined thing 'out there'. Much of our linguistic socialization in the school system dedicates itself to just this kind of ideology. From an i-language perspective, talk of catastrophe is unwarranted. Languages are not only social and cultural constructs, they are also the product of human cognition. Children create language anew with every generation. As Mougeon and Beniak (1991) make clear in their analyses of Ontarian French, language learners often re-invent the same solutions to language learning problems. They create novelties, things that no one ever exposed them to. They also fail to learn certain things. All this is normal and relatively unproblematic as long as community members are willing to classify what children say as an instance of the relevant e-language. The problem is when they will not. While a natural transmission scenario in which every generation learns a variety from their parents would be preferable to a language revitalization one; the story of Hebrew should remind us that old languages can become new languages (Belikova, 2007; Wexler, 1990). In the absence of any more native speakers, we can teach children a second language and call it 'Hebrew'. We just cannot insist that 'Hebrew' be frozen in time, forever reflecting the content of i-languages spoken by the last of the original native speakers. Exposure makes it possible but learners themselves decide what input they will make use of.

\section{References}

Altman, C., Burstein-Feldman, Z., Yitzhaki, D., Armon-Lotem, S., \& Walters, J. (2014). Family language policies, reported language use and proficiency in Russian-Hebrew bilingual

${ }^{11}$ This report deals with the social and personal outcomes on First Nations peoples of a Canadian government policy forcing their children to attend "residential" schools, often far away from their families. The explicit goal of the policy was to eliminate indigenous languages and cultural practices resulting in a legacy of alcoholism, homelessness, mental health problems and suicide among the survivors. children in Israel. Journal of Multilingual \& Multicultural Development, 35, 216-34.

Armon-Lotem, S., Joffe, S., Abutbul-Oz, H., Altman, C., \& Walters, J. (2014). Language exposure, ethnolinguistic identity and attitudes in the acquisition of Hebrew as a second language among bilingual pre-school children from Russian and English-speaking backgrounds. In T. Grüter \& J. Paradis (eds.), Input and experience in bilingual development, pp. 77-98. Amsterdam: Benjamins.

Auer, P. (ed.) (1998). Code-switching in conversation: Languages, interaction, and identity. London: Routledge.

Belikova, A. (2007). Is Modern Hebrew Semitic? One more argument in favour of the relexification hypothesis of its genesis. Paper to the 18th International Conference on historical linguistics, Université du Québec à Montréal, Montreal, August 2007.

Bernardini, P., \& Schlyter, S. (2004). Growing syntactic structure and code-mixing in the weaker language: the Ivy Hypothesis. Bilingualism: Language \& Cognition, 7, 4969.

Berwick, R. C., Pietroski, P., Yankama, B., \& Chomsky, N. (2011). Poverty of the stimulus revisited. Cognitive Science, $35,1207-1242$.

Bialystok, E. (1994). Analysis and control in the development of second language proficiency. Studies in Second Language Acquisition, 168, 157-68.

Bloom, P. (2001). How children learn the meanings of words. Cambridge, Ma: MIT Press/Bradford Books.

Bonatti, L. L., Peña, M., Nespor, M., \& Mehler, J. (2005). Linguistic constraints on statistical computations: The role of consonants and vowels in continuous speech processing. Psychological Science, 16, 451-59.

Bonnesen, M. (2009). The status of the 'weaker" language in unbalanced French/German bilingual language acquisition. Bilingualism: Language \& Cognition, 12, 177-192.

Boomer, D. S., \& Dittmann, A. T. (1962). Hesitation pauses and juncture pauses in speech. Language \& Speech, 5, 215-22.

Budzhak-Jones, S., \& Poplack, S. (1997). Two generations, two strategies: The fate of bare English-origin nouns in Ukrainian. Journal of Sociolinguistics, 1, 225-58.

Butcher, A. (1981). Aspects of the speech pause: Phonetic correlates and communicative functions. Doctoral dissertation, Institut für Phonetik, Universität Kiel, Arbeitsbericht Nr. 15

Bybee, J. L. (1995). Regular morphology and the lexicon. Language \& Cognitive Processes 10, 425-55.

Bybee, J. L. (2007). Frequency of use and the organization of language. Oxford, U.K: Oxford University Press.

Byers-Heinlein, K. (2013). Parental language mixing: its measurement and the relation of mixed input to young bilingual children's vocabulary size. Bilingualism: Language \& Cognition, 16, 32-48.

Carey, S., \& Bartlett, E. (1978). Acquiring a single new word. Papers in Reports on Child Language Development, 15, 17-29.

Carpenter, S., \& O'Connell, D. C. (1988). More than meets the ear: Some variables affecting pause reports. Language \& Communication, 8, 17-27.

Carroll, S. E. (2001). Input and evidence: the raw material of second language acquisition. Amsterdam: John Benjamins. 
Carroll, S. E. (2012). Segmentation on first exposure to an L2: evidence for knowledge-driven, top-down processing. In K. Braunmüller, C. Gabriel, \& B. Hänel-Faulhaber (eds.), HSM13 Multilingual individuals and multilingual societies, pp. 23-45. Amsterdam, N1: Benjamins.

Carroll, S. E. (2014). Processing 'words' in early stage SLA: A comparison of first exposure and early stage learners. In ZH. Han \& R. Rast (eds.), Input processing in second language acquisition, pp. 107-138. Cambridge: Cambridge University Press.

Cartmill, E. A., Armstrong, B. F. III, Gleitman, L. R., Goldin-Meadow, S., Medina, T. N., \& Trueswell, J. C. (2013). Quality of early parent input predicts child vocabulary 3 years later. Proceedings of the National Academy of Science (PNAS) 1-6, www.pnas.org/cgi/ doi/10.1073/pnas.1309518110.

Casenhiser, D., \& Goldberg, A. E. (2005). Fast mapping between a phrasal form and meaning. Developmental Science, 8 , 500-508.

Chomsky, N. (1986). Knowledge of language. New York: Praeger.

Cobo-Lewis, A. B., Pearson, B. Z., Eilers, R. E., \& Umbel, V. C. (2002a). Effects of bilingualism and bilingual education on oral and written English skills: A multi-factor study of standardized test outcomes. In D. K. Oller \& R. E. Eilers, (eds.), Language and literacy in bilingual children, pp. 6497. Clevedon, U.K: Multilingual Matters.

Cobo-Lewis, A. B., Pearson, B. Z., Eilers, R. E., \& Umbel, V. C. (2002b). Effects of bilingualism and bilingual education on oral and written Spanish skills: A multifactor study of standardized test outcomes. In D. K. Oller \& R. E. Eilers (eds.), Language and literacy in bilingual children, pp. 98117. Clevedon, U.K: Multilingual Matters.

Costa, A., Miozza, M., \& Caramazza, A. (1999). Lexical selection in bilinguals: Do words in the bilingual's two lexicons compete for selection? Journal of Memory \& Language, 41, 365-97.

Costa, A., Colomé, A., Gómez, O., \& Sebastián-Gallés, N. (2013). Another look at cross-language competition in bilingual speech production: Lexical and phonological factors. Bilingualism: Language \& Cognition, 6, 16779.

De Houwer, A. (2007). Parental input patterns and children's bilingual use. Applied Psycholinguistics, 283, 411-424.

De Houwer, A. (2014). Harmonious bilingual development: Young families' well-being in language contact situations. International Journal of Bilingualism, 19, 169-84.

Döpke, S. (2000). Generation of and retraction from cross-linguistically motivated structures in bilingual first language acquisition. Bilingualism: Language \& Cognition, 3, 209-26.

Eilers, R. E., Oller, D. K., \& Cobo-Lewis, A. B. (2002). Bilingualism and cultural assimilation in Miami Hispanic children. In D. K. Oller \& R. E. Eilers (eds.), Language and literacy in bilingual children, pp. 43-63. Clevedon, U.K: Multilingual Matters.

Elley, W. B. (1989). Vocabulary acquisition from listening to stories. Reading Research Quarterly, 24, 174-87.

Fishman, J. A. (1965). Who speaks what language to whom and when? La Linguistique, 2, 67-88.
Fodor, J. D. (1998a). Learning to parse? Journal of Psycholinguistic Research, 27, 285-319.

Fodor, J. D. (1998b). Parsing to learn. Journal of Psycholinguistic Research, 27, 339-74.

Gathercole, V. C. M. (2002a). Command of the mass/count distinction in bilingual and monolingual children: An English morphosyntactic distinction. In D. K. Oller \& R. E. Eilers (eds.), Language and literacy in bilingual children, pp. 175-219. Clevedon, U.K: Multilingual Matters.

Gathercole, V. C. M. (2002b). Grammatical gender in bilingual and monolingual children: A Spanish morpho-syntactic distinction. In D. K. Oller \& R. E. Eilers (eds.), Language and literacy in bilingual children, pp. 207-19. Clevedon, U.K: Multilingual Matters.

Gathercole, V.C.M. (2002c). Monolingual and bilingual acquisition: Learning different treatments of THAT-trace phenomena in English and Spanish. In D. K. Oller \& R. E. Eilers (eds.), Language and literacy in bilingual children, pp. 220-54. Clevedon, U.K: Multilingual Matters.

Gathercole, V. C. M. (ed.) (2007). Language transmission in bilingual families in Wales. Cardiff: Welsh Language Board.

Gathercole, V. C. M., \& Thomas, E. M. (2009). Bilingual first-language development: Dominant language takeover, threatened minority language take-up. Bilingualism: Language \& Cognition, 12, 213-237.

Gathercole, V. C. M., Thomas, E. M., \& Laporte, N. (2001). The acquisition of grammatical gender in Welsh. Journal of Celtic Language Learning. 6, 53-87.

Gregory, M., \& Carroll, S. E. (1978). Language and situation: language varieties and their social contexts. London: Routledge \& Kegan Paul.

Grosjean, F. (1982). Life with two languages: An introduction to bilingualism. Cambridge, Ma: Harvard University Press.

Grosjean, F. (1985). The bilingual as a competent but specific speaker-hearer. Journal of Multilingual \& Multicultural Development, 6, 467-477.

Grosjean, F. (1989). Neurolinguists beware! The bilingual is not two monolinguals in one person. Brain \& Language, 36, $3-15$.

Grüter, T., \& Paradis, J. (2014). Introduction to Input and experience in bilingual development. In T. Grüter \& J. Paradis (eds.), Input and experience in bilingual development, pp. 1-14. Amsterdam, N1: John Benjamins.

Grüter, T., Hurtado, N., Marchman, V. A., \& Fernald, A. (2014). Language exposure and online processing efficiency in bilingual development: Relative versus absolute measures. In T. Grüter \& J. Paradis (eds.), Input and experience in bilingual development, pp. 15-36. Amsterdam, N1: John Benjamins.

Gullberg, M., Roberts, L., Dimroth, C., Veroude, K., \& Indefrey, P. (2010). Adult language learning after minimal exposure to an unknown natural language. Language Learning, 60, Suppl. 2, pp. 5-24.

Heibeck, T. H., \& Markman, E. M. (1987). Word learning in children: An examination of fast mapping. Child Development, 58, 1021-34.

Hoff, E. (2014). Language development. $5^{\text {th }}$ edition. Belmont, Ca: Wadsworth Cengage Learning. 
Jackendoff, R. (2002). Foundations of language. Brain, meaning, grammar, evolution. Oxford: Oxford University Press.

Kalishnikova, M., Mattock, K., \& Monaghan, P. (2015). The effects of linguistic experience on the flexible use of mutual exclusivity in word learning. Bilingualism: Language \& Cognition, 18, 626-638.

La Morgia, F. (2011). Bilingual first language acquisition: The nature of the weak language and the role of the input. Doctoral dissertation, SALIS, Dublin City University. Republic of Ireland.

Lanza, E. (1992). Can bilingual two-year olds code-switch? Journal of Child Language, 19, 633-58.

Lanza, E. (1997). Language mixing in infant bilingualism: A sociolinguistic perspective. Oxford: Clarendon.

MacWhinney, B. (1987). The Competition Model. In B. MacWhinney (ed.), Mechanisms of language acquisition, pp. 249-308. Hillsdale, N.J: Erlbaum.

MacWhinney, B. (2005). New directions in the Competition Model. In M. Tomasello \& D. I. Slobin (eds.), Beyond nature-nurture: Essays in honor of Elizabeth Bates, pp. 81-110. Mahwah, N.J: Erlbaum.

Marcus, G. F., Pinker, S., Ullman, M., Hollander, M., Rosen, T. J., \& Xu, F. (1992). Over-regularisation in language acquisition. Monographs of the Society for Research in Child Development Serial No. 228, Vol 57 (4), pp. i-178.

Markson, L., \& Bloom, P. (1997). Evidence against a dedicated system for word learning in children. Nature, 385 (6619), 813-15.

Medina, T. N., Snedeker, J., Trueswell, J. C., \& Gleitman, L. R. (2011). How words can and cannot be learned by observation. Proceedings of the National Academy of Sciences USA, 108, 9014-19.

Meisel, J. M. (1985). Les phases initiales du développement des notions temporelles, aspectuelles et de modes d'action. Lingua, 66, 321-74.

Meisel, J. M. (1986). Word order and case-marking in early child language: Evidence from simultaneous acquisition of two first languages: French and German. Linguistics, 24, 12383.

Meisel, J. M. (1989). Early differentiation of languages in bilingual children. In K. Hyltenstam \& L. Obler (eds.), Bilingualism across the lifespan, pp. 13-40. Cambridge: Cambridge University Press.

Meisel, J. M. (1991). Principles of universal grammar and strategies of language learning: Some similarities and differences between first and second language acquisition. In L. Eubank (ed.), Point Counterpoint, pp. 231-76. Amsterdam: John Benjamins.

Meisel, J. M. (1994). Getting FAT. Finiteness, agreement and tense in early grammars. In J. M. Meisel (ed.), Bilingual first language acquisition: French and German grammatical development, pp. 89-129. Amsterdam: Benjamins.

Meisel, J. M. (1997). The acquisition of the syntax of negation in French and German: Contrasting first and second language development. Second Language Research, 13, 22763.

Meisel, J. M. (2007a). Exploring the limits of the LAD. Working Papers in Multilingualism 80. Series B. University of Hamburg.
Meisel, J. M. (2007b). The weaker language in early child bilingualism: Acquiring a first language as a second language? Applied Psycholinguistics, 28, 495-514.

Meisel, J. M. (2011). First and second language acquisition: Parallels and differences. Cambridge, U.K: Cambridge University Press.

Meisel, J. M. (2013). Sensitive phases in successive language acquisition: The Critical Period Hypothesis revisited. In C. Boeckx \& K. Grohmann (eds.), Handbook of biolinguistics, pp. 69-85. Cambridge: Cambridge University Press.

Morgan, J. L. (1986). From simple input to complex grammar. Cambridge, Ma: MIT Press.

Morgan, J. L. (1990). Input, innateness, and induction in language acquisition. Developmental Psychobiology, 23, 661-78

Morgan, J. L., \& Demuth, K. (eds.) (1996). Signal to syntax: Bootstrapping from speech to grammar in early acquisition. Hillsdale, N.J: Erlbaum.

Mougeon, R., \& Beniak, E. (1991). Linguistic consequences of language contact and restriction: The case of French in Ontario, Canada. Oxford: Clarendon Press.

Naigles, L. R. (1990). Children use syntax to learn verb meanings. Journal of Child Language, 17, 357-74.

Oller, D. K. (2005). The distributed characteristic in bilingual learning. In J. Cohen, K. McAlister, K. Rolstad, \& J. MacSwan (eds.), Proceedings of the 4th International Symposium on Bilingualism, pp. 1744-49. Somerville, Ma: Cascadilla Press.

Oller, D. K., \& Eilers, R. E. (2002). An integrated approach to evaluating effects of bilingualism in Miami school children: The study design. In D. K. Oller \& R. E. Eilers (eds.), Language and literacy in bilingual children, pp. 22-40. Clevedon, U.K: Multilingual Matters.

Oller, D. K., \& Pearson, B. Z. (2002). Assessing the effects of bilingualism: a background. In D. K. Oller \& R. E. Eilers (eds.), Language and literacy in bilingual children, pp. 321. Clevedon, U.K: Multilingual Matters.

ORiagáin, P. Ó. (2008). Language attitudes and minority languages. In N. H. Hornberger (ed.), Encyclopedia of Language and Education, pp. 2077-2089. Berlin: Springer.

O'Rourke, B. (2005). Attitudes towards minority languages: An investigation of young people's attitudes towards Irish and Galician. Doctoral thesis, Dublin City University.

Paradis, J. (2010). Bilingual children's acquisition of English verb morphology: Effects of language exposure, structure complexity, and task type. Language Learning, 60, 65180.

Paradis, J., \& Genesee, F. (1996). Syntactic acquisition in bilingual children: Autonomous or independent? Studies in Second Language Acquisition, 18, 1-25.

Paradis, J., \& Navarro, S. (2003). Subject realisation and cross-linguistic interference in the bilingual acquisition of Spanish and English: What is the role of input? Journal of Child Language, 30, 1-23.

Patterson, J. (1998). Expressive vocabulary development and word combinations of Spanish-English bilingual toddlers. American Journal of Speech-Language Pathology, 7, 4656. 
Pearson, B. Z. (2007). Social factors in childhood bilingualism in the United States. Applied Psycholinguistics, 28, 399410.

Pearson, B. Z., \& Amaral, L. (2014). Interactions between input factors in bilingual language acquisition: Considerations for minority language maintenance. In T. Grüter \& J. Paradis (eds.), Input and experience in bilingual development, pp. 99-117. Amsterdam: Johnbrk Benjamins.

Pearson, B. Z., Fernández, S. C., Lewedeg, V., \& Oller, D. K. (1997). The relation of input factors to lexical learning by bilingual infants. Applied Psycholinguistics, 18, 4158.

Piattelli-Palmarini, M., \& Berwick, R. C. (eds.) (2012). Rich languages from poor inputs. Oxford: Oxford University Press.

Pinker, S. (1999). Words and rules: the ingredients of language. New York: Harper Collins.

Place, S., \& Hoff, E. (2011). Properties of dual language exposure that influence two-year-olds' bilingual proficiency. Child Development, 82, 1834-49.

Poplack, S., \& Sankoff, S. (1984). Borrowing: The synchrony of integration. Linguistics, 22, 99-135.

Poplack, S., Wheeler, S., \& Westwood, A. (1989). Distinguishing language contact phenomena: Evidence from FinnishEnglish bilingualism. In K. Hyltenstam \& L. K. Obler (eds.), Bilingualism across the lifespan, pp. 132-54. Cambridge: Cambridge University Press.

Rohde, A., \& Tiefenthal, C. (2000). Fast mapping in naturalistic L2 acquisition. Studia Linguistica, 54, 167-74.

Scheele, A. F., Leseman, P. P. M., \& Mayo, A. Y. (2010). The home language environment of monolingual and bilingual children and their language proficiency. Applied Psycholinguistics, 31, 117-40.

Schlyter, S. (1993). The weaker language in bilingual SwedishFrench children. In K. Hyltenstam \& A. Viberg (eds.), Progression and regression in language: Sociocultural, neuropsychological and linguistic perspectives pp. 289308. Cambridge: Cambridge University Press.

Segalowitz, N. (2003). Automaticity and second languages. In C. J. Doughty \& M. H. Long (eds.), The handbook of second language acquisition, pp. 382-408. Oxford: Oxford University Press.
Silva-Corvalán, C. (2014). Bilingual language acquisition: Spanish and English in the first six years. Cambridge: Cambridge University Press.

Thomas, E. M., \& Gathercole, V. C. M. (2005). Minority language survival: Obsolescence or survival for Welsh in the face of English dominance? In J. Cohen, K. McAlister, K. Rolstad, \& J. MacSwan (eds.), ISB4: Proceedings of the 4th International Symposium on Bilingualism, pp. 223357. Somerville, Ma: Cascadilla Press.

Thomas, E. M., \& Gathercole, V. C. M. (2007). Children's productive command of grammatical gender and mutation in Welsh: An alternative to rule-based learning. First Language, 27, 251-78.

Thomas, E. M., Williams, N., Jones, L. A., Davies, S., \& Binks, H. (2013). Acquiring complex structures under minority language conditions: Bilingual acquisition of plural morphology in Welsh. Bilingualism: Language \& Cognition, 17, 478-94.

Truth and Reconciliation Commission of Canada. (2012). They came for the children. Canada, aboriginal peoples and residential schools. Winnipeg, MB: Librairies \& Archives Canada.

Unsworth, S. (2013). Assessing the role of current and cumulative exposure in simultaneous bilingual acquisition: The case of Dutch gender. Bilingualism: Language \& Cognition, 16, 86-110.

Weisleder, A., \& Fernald, A. (2013). Talking to children matters: Early language experience strengthens processing and builds vocabulary. Psychological Science, 24, 2143-52.

Weissenborn, J., \& Höhle, B. (eds.) (2001). Approaches to bootstrapping. Phonological, lexical, syntactic and neurophysiological aspects of early language acquisition. 2 vols. Amsterdam: Benjamins.

Wexler, P. (1990). The schizoid nature of Modern Hebrew: A Slavic language in search of a Semitic past. Wiesbaden: Otto Harrassowitz.

Woodward, A. L., Markman, E. M., \& Fitzsimmons, C. M. (1994). Rapid word learning in 13- and 18-month-olds. Developmental Psychology, 30, 553-66.

Yang, C. D. (2002). Knowledge and learning in natural language. Oxford: Oxford University Press.

Yip, V., \& Matthews, S. (2006). Assessing language dominance in bilingual acquisition: A case for mean length utterance differentials. Language Assessment Quarterly, 3, 97-116. 